\title{
Fatty foci within the heart and the accompanying changes in the coronary arteries diagnosed in electrocardiogram-gated multislice computed tomography of the heart
}

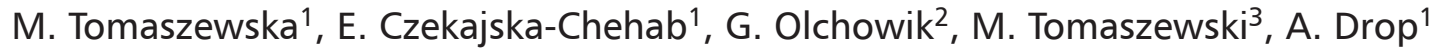 \\ ${ }^{1} 1^{\text {st }}$ Department of Radiology, Medical University of Lublin, Lublin, Poland \\ ${ }^{2}$ Department of Biophysics Medical University of Lublin, Lublin, Poland \\ ${ }^{3}$ Department of Human Anatomy Medical University of Lublin, Lublin, Poland
}

[Received 9 April 2014; Accepted 3 June 2014]

Background: The purpose of our study was to analyse the relationship between fatty foci within the heart and the accompanying changes in the coronary arteries supplying the relevant heart chambers in a large group of patients referred to multi-slice computed tomography with electrocardiogram-gating examinations (ECG-MSCT) for various clinical reasons.

Materials and methods: The ECG-MSCT examinations of 1,830 consecutive patients were analysed. The examinations were performed using 8-row (1,015 patients) and 64-row (815 patients) MSCT, in pre- and postcontrast scanning. In the group of patients with fatty foci within the heart the concomitant changes in the coronary arteries were assessed. It was analysed: the type of changes in the arteries; the relationship between the locations of the fatty deposits and the occurrence and type of changes in the coronary arteries.

Results: In 200 (10.9\%) subjects fatty foci within the heart $(112$ men; 88 women; mean age 57.8) were detected. The distribution of the fat was as follows: right ventricle $(R V)-32.5 \%$, left ventricle $(L V)-22.0 \%$, biventricular $-45.5 \%$. One hundred and seventy-two patients had concomitant changes in the coronary arteries. In patients with normal coronary arteries, significantly more often fatty deposits were localised within RV. Fat was primarily located subendocardially in the $L V$ in patients with atherosclerosis in the left anterior descending artery $(p<0.001)$, in the right coronary artery $(R C A)(p=0.003)$, and in the left circumflex artery $(L C X)(p<0.001)$. Subpericardial locations of fatty deposits in RV significantly correlated with RCA bridging ( $p<0.02)$; the subpericardial location of fat in LV significantly correlated with LCX bridging ( $p=0.001)$.

Conclusions: Fatty replacement of the myocardium is common, occurring in up to $10 \%$ of diagnosed patients and the majority of this group had concomitant changes in the coronary arteries. However, in the group of patients without changes in the coronary arteries, the fatty deposits locate themselves significantly more frequently within the RV. (Folia Morphol 2014; 73, 4: 445-461)

Key words: ECG-MSCT, myocardium, fat, coronary arteries

Address for correspondence: M. Tomaszewska, MD, PhD, $1^{\text {st }}$ Radiology Department, Medical University of Lublin, ul. Jaczewskiego 8 , 20-954 Lublin, Poland, tel: +48 817244 660, e-mail: mon.tomaszewska@gmail.com 


\section{INTRODUCTION}

The development of electrocardiogram-gated multi-slice computed tomography (ECG-MSCT) has not only enabled diagnosis of changes in the myocardium, but also of coronary artery disease (CAD). The constantly increasing number of ECG-MSCT examinations poses a challenge for the radiologists when assessing the changes being identified in the heart - including the increasingly frequent identification of fatty deposits. The most commonly reported diseases, where there is fat infiltration of the myocardium, are arrhythmogenic right ventricular dysplasia (ARVD), tuberous sclerosis and scar tissue following myocardial infarction (MI) $[1-3,8,13,15]$. However, fatty infiltration of the right ventricle can also be present in healthy people $[9,10]$.

There is little available literature regarding the comprehensive assessment of the relationship between changes in the coronary arteries and fatty foci within the walls of the heart.

The aim of our study was to analyse the relationship between fatty deposits in the myocardium and the accompanying changes in the coronary arteries in patients referred for an ECG-MSCT examination for various clinical reasons.

\section{MATERIALS AND METHODS}

The ECG-MSCT examinations of 1,830 patients (802 women, 1,028 men), averaging 53.5 years of age (range 6-90 years of age) were retrospectively analysed regarding the occurrence fatty foci within the heart. The patients were referred for ECG-MSCT examinations for different clinical reasons (the suspicion of CAD, positive exercise test, status after MI, arrhythmias, status after cardiac surgery, chest pain). This study was approved by the Bioethical Committee of the Medical University of Lublin, Poland (number KE-0254/153/2009) and patient consent was waived.

Examination of 1,015 patients was performed using an 8-slice scanner (LightSpeed Ultra, GE Medical Systems), while in the case of 815 patients a 64-slice scanner was used (LightSpeed VCT GE Medical Systems, Milwaukee, Wisconsin).

The examinations were performed in layers: $2.5 \mathrm{~mm}$ in native scans and $0.625 \mathrm{~mm}$ (64-row CT) or $1.25 \mathrm{~mm}$ (8-row CT) after intravenous administration of contrast medium - a bolus of $70-100 \mathrm{~mL}$ of Ultravist (iopromide) $370 \mathrm{mgl} / \mathrm{mL}$ at a rate of $4-5 \mathrm{~mL} / \mathrm{s}$, followed by $30 \mathrm{~mL}$ of saline at $4-5 \mathrm{~mL} / \mathrm{s}$ (64-row CT). In all cases retrospective ECG-gating was employed. When necessary, patients received $25-50 \mathrm{mg}$ of oral metoprolol for heart rate reduction administered 30-60 min prior to examination. Reconstruction windows were set manually, depending on heart size, field of view 20-27 cm and a few centimetres above the tracheal bifurcation and below the lower heart border. The output data were sent to diagnostic console after scanning (Advantage Workstation 4.2 or 4.3, GE Medical Systems). Two experienced radiologists analysed all ECG-MSCT images.

Fatty changes were defined as areas with negative Hounsfield Unit (HU) values in native or enhanced phase of examination.

In the group of patients with fatty foci within the heart were analysed concomitant changes in the coronary arteries supplying the relevant heart ventricles (atherosclerotic changes and the presence of myocardial bridges).

Patients with changes in the coronary arteries were included in one of the following groups: (i) atherosclerosis only; (ii) myocardial bridges only; (iii) atherosclerosis and myocardial bridges.

Atherosclerotic changes in the coronary arteries, were then qualified as: (i) mild stenosis (luminal diameter stenosis $\leq 50 \%)$; (ii) critical stenosis $(50 \%>$ luminal diameter stenosis < 99\%); (iii) occlusion (luminal diameter stenosis $\geq 99 \%$ ).

The relationship between the locations of the fatty deposits in the heart, and the occurrence and type of changes in the coronary arteries was also analysed.

The group of patient who had MI or CAD were selected in order to assess the distribution of fatty deposits within the heart and the accompanying changes in the coronary arteries.

The collected data was statistically analysed using Statistica 9.0. The $\chi^{2}$ test were used to determine the significance between variables. A value of $p<0.05$ was considered statistically significant.

\section{RESULTS}

Presence of fatty foci in the heart muscle was diagnosed in 200 patients (10.9\% of the analysed group).

Patients with fatty foci within the heart muscle included $112(11.0 \%)$ of analysed male group and $88(11.1 \%)$ of female group averaging 57.8 years of age. The average body mass index in our study group was elevated (28.0 in females, 27.9 in males).

The distribution of fat in 200 patients was as follows: right ventricle (RV) - 65 (32.5\%) patients, left ventricle (LV) - $44(22 \%)$ and biventricular - 91 (45.5\%). 
Table 1. The location of the fatty foci within the heart according to the accompanying changes in the coronary arteries; $p<0.05$

\begin{tabular}{lcc}
\hline Type of changes in the coronary arteries & The location of the fatty foci & No. of patients \\
\hline Without changes in the coronary arteries $(n=28)$ & RV $(n=65)$ & 17 \\
& $\operatorname{LV}(n=44)$ & 4 \\
\hline Atherosclerotic changes $(\mathrm{n}=58)$ & $\mathrm{RV}(\mathrm{n}=65)$ & 15 \\
& $\mathrm{LV}(\mathrm{n}=44)$ & 15 \\
\hline Myocardial bridges $(\mathrm{n}=32)$ & $\mathrm{RV}+\mathrm{LV}(\mathrm{n}=91)$ & 28 \\
\hline Atherosclerotic changes and myocardial bridges $(\mathrm{n}=82)$ & $\mathrm{RV}(\mathrm{n}=65)$ & 2 \\
\hline & $\mathrm{LV}(\mathrm{n}=44)$ & 11 \\
\hline
\end{tabular}

LV — left ventricle; RV — right ventricle

Significant correlations ( $p<0.05$ ) were found between the distribution of fatty deposits in the heart ventricles and the nature of the changes in the coronary arteries supplying the relevant parts of the heart (Table 1).

It is worth noting that, in patients without changes in the coronary arteries, significantly more often fatty deposits were localised within the RV (Fig. 1). In patients with fatty deposits only in the LV, or in both ventricles, simultaneous occurrence of atherosclerosis and myocardial bridges was identified most commonly.

Atherosclerosis in the right coronary artery (RCA) was identified in 103 (50.5\%) patients; in the left anterior descending artery (LAD) in 130 (64.0\%) patients; in the left circumflex artery (LCX) in 90 (44.0\%) patients. Myocardial bridges over the RCA was identified in 9 (4.4\%) patients, over the LAD in 98 (48\%) patients, and over the LCX in 52 (25.5\%) patients.

The study analysed the differences between changes in the coronary arteries supplying their associated ventricle and the location of fatty deposits within the heart (Table 2).

Significant differences $(p<0.03$ ) were found between atherosclerosis in the RCA and the location of fatty deposits in the heart. In the case of atherosclerosis in the RCA fatty deposits were located most commonly simultaneously in the both ventricles $(p<0.03)$. A similar statistically significant correlation was found for the biventricular distribution of fatty deposits and atherosclerosis in the LAD.

In the study it was also analysed the relationship between the types of changes in the coronary arteries

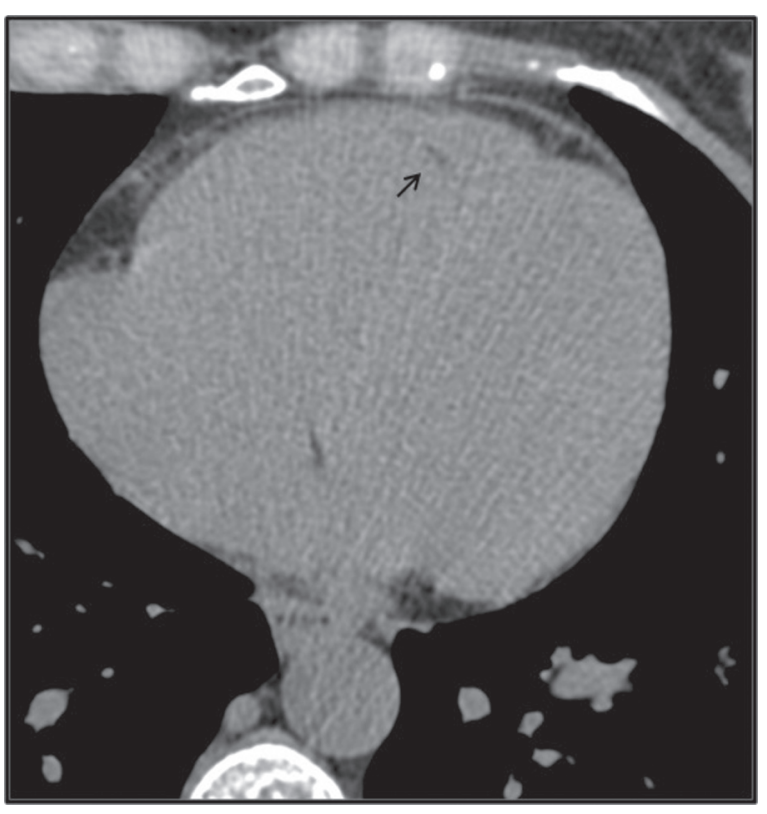

Figure 1. Linear fatty focus (arrow) localised subendocardially in the right ventricle in 43-year-old patient with normal coronary arteries.

and the specific localisation of fatty deposits in heart wall (Table 3).

Analysing the location of fatty deposits in the heart wall, subendocardially located fatty foci in the LV were significantly more common in patients with atherosclerosis in the LAD $(p<0.001), \operatorname{RCA}(p=0.003)$, and LCX ( $p<0.001)$. In addition, significant correlations were observed between the subpericardial locations of fatty deposits in the RV and myocardial bridges over the RCA $(p<0.02)$ and between the 
Table 2. The location of fatty deposits within the heart according to the type of changes in the coronary arteries

\begin{tabular}{lcccccc}
\hline $\begin{array}{l}\text { The location } \\
\text { of fatty deposits } \\
\text { within the heart }\end{array}$ & $\begin{array}{c}\text { RCA } \\
\text { atherosclerosis* }\end{array}$ & $\begin{array}{c}\text { RCA } \\
\text { bridging* }\end{array}$ & $\begin{array}{c}\text { LAD } \\
\text { atherosclerosis* }\end{array}$ & $\begin{array}{c}\text { LAD } \\
\text { bridging* }\end{array}$ & $\begin{array}{c}\text { LCX } \\
\text { atherosclerosis* }\end{array}$ & $\begin{array}{c}\text { LCX } \\
\text { bridging* }\end{array}$ \\
\hline RV & $24(23.4 \%)$ & $2(22.3 \%)$ & $36(27.7 \%)$ & $29(29.6 \%)$ & $27(30.0 \%)$ & $2(3.8 \%)$ \\
LV & $31(30.1 \%)$ & $1(11.1 \%)$ & $37(28.5 \%)$ & $21(21.4 \%)$ & $28(31.1 \%)$ & $10(19.2 \%)$ \\
RV + LV & $48(46.5 \%)$ & $6(66.6 \%)$ & $57(43.8 \%)$ & $48(49.6 \%)$ & $35(38.9 \%)$ & $30(77.0 \%)$ \\
P & $<0.03$ & 0.8 & $<0.05$ & 0.1 & 0.08 & 0.5 \\
\hline
\end{tabular}

${ }^{*}$ No. of affected vessels (\%); RCA — right coronary artery; LAD — left anterior descending artery; LCX — left circumflex artery; LV — left ventricle; RV — right ventricle

Table 3. Localisation of fatty foci within the heart wall with regards to the type of changes in the coronary arteries

\begin{tabular}{lcc}
\hline $\begin{array}{l}\text { Type of changes } \\
\text { in the coronary } \\
\text { arteries }\end{array}$ & $\begin{array}{c}\text { The location } \\
\text { of the fatty foci }\end{array}$ & $\begin{array}{c}\text { No. of } \\
\text { affected } \\
\text { vessels }\end{array}$ \\
\hline RCA atherosclerosis & LV subendocardially & $47^{*}$ \\
& LV subpericardially & 17 \\
& RV subendocardially & 20 \\
& RV subpericardially & 24 \\
\hline RCA bridging & LV subendocardially & 3 \\
& LV subpericardially & 2 \\
& RV subendocardially & 3 \\
& RV subpericardially & $6 *$ \\
\hline LAD atherosclerosis & LV subendocardially & $55^{*}$ \\
& LV subpericardially & 23 \\
& RV subendocardially & 31 \\
& RV subpericardially & 35 \\
\hline LCX bridging & LV subendocardially & 40 \\
& LV subpericardially & 20 \\
& RV subendocardially & 29 \\
& RV subpericardially & 26 \\
\hline LCX atherosclerosis & LV subendocardially & $44^{*}$ \\
& LV subpericardially & 13 \\
& RV subendocardially & 19 \\
& RV subpericardially & 24 \\
\hline LV subendocardially & 21 \\
& LV subpericardially & $16^{*}$ \\
& RV subendocardially & 13 \\
& RV subpericardially & 15 \\
\hline & & \\
& &
\end{tabular}

${ }^{*} p<0.05$ - statistically significant; abbreviations as in Table 2

subpericardial location of fatty deposits in the LV and myocardial bridges over the LCX $(p=0.001)$.

The study evaluated the advance of atherosclerosis in the coronary arteries supplying the relevant heart ventricles (Table 4).
Table 4. The advance of atherosclerosis in the coronary arteries and localisation of fatty foci within the heart ventricles

\begin{tabular}{|c|c|c|}
\hline $\begin{array}{l}\text { The advance of } \\
\text { atherosclerosis }\end{array}$ & $\begin{array}{l}\text { The localisation } \\
\text { of the fatty foci }\end{array}$ & $\begin{array}{l}\text { No. of affected } \\
\text { vessels }\end{array}$ \\
\hline \multicolumn{3}{|l|}{$\mathrm{RCA}(\mathrm{n}=103)$} \\
\hline \multirow[t]{3}{*}{ Mild stenosis } & $\mathrm{RV}$ & 19 \\
\hline & LV & 18 \\
\hline & $\mathrm{RV}+\mathrm{LV}$ & 31 \\
\hline \multirow[t]{3}{*}{ Critical stenosis } & RV & 1 \\
\hline & LV & 8 \\
\hline & $\mathrm{RV}+\mathrm{LV}$ & 6 \\
\hline \multirow[t]{3}{*}{ Occlusion } & RV & 4 \\
\hline & LV & 5 \\
\hline & $\mathrm{RV}+\mathrm{LV}$ & 11 \\
\hline \multicolumn{3}{|l|}{$\operatorname{LAD}(n=130)$} \\
\hline \multirow[t]{3}{*}{ Mild stenosis } & RV & 23 \\
\hline & LV & 20 \\
\hline & $\mathrm{RV}+\mathrm{LV}$ & 34 \\
\hline \multirow[t]{3}{*}{ Critical stenosis } & RV & 9 \\
\hline & $\mathrm{LV}$ & 8 \\
\hline & $\mathrm{RV}+\mathrm{LV}$ & 18 \\
\hline \multirow[t]{3}{*}{ Occlusion } & RV & 4 \\
\hline & LV & 8 \\
\hline & $\mathrm{RV}+\mathrm{LV}$ & 6 \\
\hline \multicolumn{3}{|l|}{$\operatorname{LCX}(n=90)$} \\
\hline \multirow[t]{3}{*}{ Mild stenosis } & RV & 18 \\
\hline & LV & 17 \\
\hline & $\mathrm{RV}+\mathrm{LV}$ & 23 \\
\hline \multirow[t]{3}{*}{ Critical stenosis } & RV & 7 \\
\hline & $\mathrm{LV}$ & 7 \\
\hline & $\mathrm{RV}+\mathrm{LV}$ & 8 \\
\hline \multirow[t]{3}{*}{ Occlusion } & $\mathrm{RV}$ & 2 \\
\hline & LV & 4 \\
\hline & $\mathrm{RV}+\mathrm{LV}$ & 4 \\
\hline
\end{tabular}

Abbreviations as in Table 2 
In patients with fatty deposits in the RV the most common mild stenosis of the LAD was observed. In patients with fatty deposits in the LV also mild stenoses of the RCA, the LAD and the LCX were noted. Of all the cases of occlusions, in group of patients with fat within the LV, the highest number of LAD occlusions was noted. However, for the simultaneous occurrence of fatty deposits in both ventricles, the most common changes were mild stenosis in the RCA and $L A D$ and this group also recorded the highest number of occlusions (21 cases).

Taking into account clinical diagnosis, the study group consisted of 42 patients who had MI and 57 with suspected CAD. The locations of the fatty deposits in these patients are shown in Tables 5 and 6 .

There were significant differences in the locations of the fatty deposits depending on clinical diagnosis. In patients who had MI the fatty deposits occurred most commonly in the LV, whilst in patients with ischaemia the changes were located primarily in both ventricles. In patients who had Ml, the fatty deposits were located significantly more often in the subendocardium of the LV (Fig. 2).

\section{DISCUSSION}

Fatty deposits within the heart were found in 200 patients (10.9\% of the study group). Of these, 172 patients also had changes in their coronary arteries, whilst 28 did not.

There were significant differences between the distribution of fatty deposits in the heart and accompanying changes in the coronary arteries. In the group of patients with normal coronary arteries, significantly more often fatty deposits were localised within the RV.

The most frequently reported disease in which there is fat infiltration into the muscle of the RV is ARVD. ARVD is a disease characterised by fibro-fatty replacement of the ventricular myocardium $[8,13]$. Dysplastic changes are localised within the RV free wall and are located in the so-called "triangle of dysplasia" which is an area between the tip, funnel and RV outflow tract. As a result, weakening of the ventricular wall occurs causing RV enlargement and the formation of aneurysms. In these patients ventricular tachycardia appears, which leads to premature death [12].

However, adipose tissue within the RV may also be present in patients without any clinical symptoms. Already in 1959, Bronzini and Novi [4] following their histopathological examination of 40 fatty hearts noticed that the layer of adipose tissue in the epicar-
Table 5. The localisation of the fatty foci in particular heart ventricles in patients after myocardial infarction (MI) and with suspected coronary artery disease (CAD); $p<0.001$

\begin{tabular}{lcc}
\hline Clinical diagnosis & Location of fatty foci & No. of patients \\
\hline MI & RV & 7 \\
& LV & 22 \\
& RV + LV & 13 \\
\hline CAD & RV & 22 \\
& LV & 8 \\
& RV + LV & 27 \\
\hline
\end{tabular}

Abbreviations as in Table 2

Table 6. The localisation of the fatty deposits within the heart wall in patients after myocardial infarction (MI) and with suspected coronary artery disease (CAD)

\begin{tabular}{lcc}
\hline $\begin{array}{l}\text { Clinical } \\
\text { diagnosis }\end{array}$ & \multicolumn{1}{c}{$\begin{array}{c}\text { Location } \\
\text { of fatty foci }\end{array}$} & $\begin{array}{c}\text { No. of patients } \\
(\%)\end{array}$ \\
\hline $\mathrm{MI}$ & LV subendocardially $(\mathrm{n}=42)$ & $31^{*}(74 \%)$ \\
& LV subpericardially $(\mathrm{n}=14)$ & $8(57 \%)$ \\
& RV subendocardially $(\mathrm{n}=23)$ & $10(43 \%)$ \\
& RV subpericardially $(\mathrm{n}=26)$ & $9(35 \%)$ \\
\hline CAD & LV subendocardially $(\mathrm{n}=42)$ & $12(26 \%)$ \\
& LV subpericardially $(\mathrm{n}=14)$ & $6(43 \%)$ \\
& RV subendocardially $(\mathrm{n}=23)$ & $13(57 \%)$ \\
& RV subpericardially $(\mathrm{n}=26)$ & $17(65 \%)$ \\
\hline
\end{tabular}

${ }^{*} \mathrm{p}<0.05-$ statistically significant; abbreviations as in Table 2

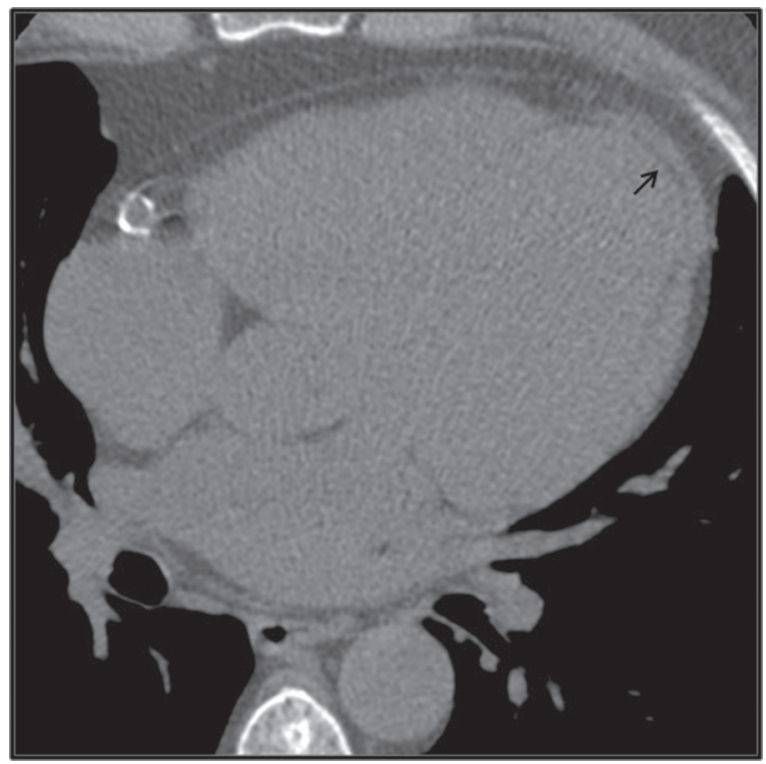

Figure 2. Linear subendocardial fatty focus (arrow) in the left ventricle in 45 -year-old patient after myocardial infarction. 
dium was significantly greater on the surface of the $\mathrm{RV}$. They also showed that fat cells can infiltrate the myocardium layer.

In the cardiac CT studies it was found that the incidence of fatty changes within the heart increases with the age of the patients $[5,8,9,16]$. Physiologic fat is located in the anterolateral RV free wall, RV outflow tract, and sometimes in RV trabeculae and the apex of the heart. In these cases the myocardial wall is either normal or thick [10]. Kirsch et al. [11] showed that there is no correlation between the presence of the fat in the RV and the body mass index of patients.

Of those patients with fatty changes in the RV, almost $75 \%$ of them had associated changes in the coronary arteries. This data is similar to the results reported by Imada et al. [6], who so far have been the only ones who have analysed changes in coronary arteries in patients with fat infiltration of the anterior wall of the RV. The authors evaluated 49 patients who were diagnosed in ECG-gated MSCT examinations $76 \%$ of them had calcified and $24 \%$ had non-calcified atherosclerotic plaques in the coronary arteries.

Of all the assessed types of changes in the coronary arteries, a significant correlation was found between the occurrence of the muscle bridges over the RCA and the subepicardial location of fatty deposits in the RV. This may suggest a relationship between the influence of transitional episodes of myocardial ischaemia on the initiation of fatty metaplasia.

Fatty foci may be present also within the scar after a healed MI [18]. The presence of fat in the post-infarction scar in post mortem material was described for the first time in 1997 [2].

The presence of myocardial fatty metaplasia in post-Ml patients was first diagnosed in vivo in 2004 [17]. The proposed mechanism responsible for this process is probably related to the presence of multipotential cells in the myocardium which, in response to an external stimulus (e.g. the therapeutic process), differentiate into fat cells [3].The incidence of fatty changes after MI correlates with increased age, the male sex, and after placement of a coronary artery by-pass graft [15].

Raney et al. [14] analysed the ECG-MSCT (64-slice scanner; Toshiba Aquilion, Tustin, CA) examinations of 100 healthy patients and 25 patients after MI. Authors concluded that RV myocardial fat correlates with increased age in healthy populations, while LV myocardial fat most commonly was associated with MI. The similar dependence was found in our study-in the group of patients after MI most often fatty foci were localised subendocardially in the LV. A similar dependence was described by Kimura et al. [10]. In patients without changes in the coronary arteries, significantly more often fatty deposits were localised within the RV.

Analysing the fatty deposits in the LV, a significant relationship was found between the type of changes in the coronary arteries and the presence of fatty deposits in the heart; in these group of patients most commonly both atherosclerosis and muscle bridges over the path of the arteries supplying the LV were observed. A significant relationship was found between the subendocardial location of the fatty deposits and atherosclerosis within the RCA, LAD and LCX arteries. In addition, in patients in whom the muscle bridge over the LCX was seen, significantly more fatty deposits were located subepicardially in the LV.

Of those patients with fatty changes in the LV, only $9 \%$ had no associated changes in the coronary arteries. Raney et al. [14] noticed that fatty foci in the LV may be also present in healthy populations, but in these cases the optical density of fatty lesions is significantly higher compared to infarcted group. Authors also concluded that healthy men had a lower risk of fatty lesion within the LV.

Assessing the distribution of fat within the heart it was found that these deposits most frequently occur in both ventricles ( $45.5 \%$ of patients). Jacobi et al. [7] analysed the fatty deposits located in both ventricles. Authors analysed 1,846 non-contrast chest CT studies without ECG-gating. Fatty deposits were identified in $26(1.4 \%)$ patients. Fat was detected in the RV in $27 \%$ of patients, in the LV in $46 \%$ of patients and biventricularly in $27 \%$ of patients. The patients with fatty metaplasia of the RV were statistically older compared to the group of patients with fatty deposits in the LV. Fifty per cent of patients with fatty metaplasia of the LV had MI in the past. Only 1 patient in the analysed group had histologically confirmed ARVD. In this case fat was localised simultaneously in both ventricles.

In our study the fatty foci occurring simultaneously in both ventricles were reported significantly more often in patients with atherosclerosis in the RCA and LAD arteries. On the other hand, taking into account clinical diagnosis, a significant relationship was found between CAD and biventricular location of fatty deposits.

\section{Limitations of the study}

There are some limitations of this study. First of all, it includes a retrospective analysis. Secondly, in 
many cases there is the lack of the opportunities to deepen the clinical analysis. Thirdly, the assessment of fatty deposits and coronary artery abnormalities using a 8-row MDCT might have been inadequate and difficult to compare with the 64-row MDCT scanner.

\section{CONCLUSIONS}

Fatty replacement of the heart is common, occurring in up to $10 \%$ of diagnosed patients and the majority of this group had concomitant changes in the coronary arteries. However, in the group of patients without changes in the coronary arteries, the fatty deposits locate themselves significantly more frequently within the right ventricle.

\section{REFERENCES}

1. Adriaensen ME, Schaefer-Prokop CM, Duyndam DA, Zonnenberg BA, Prokop M (2009) Fatty foci in the myocardium in patients with tuberous sclerosis complex: common finding at CT. Radiology, 253: 359-363.

2. Baroldi G, Silver MD, De Maria R, Parodi O, Pellegrini A (1997) Lipomatous metaplasia in left ventricular scar. Can J Cardiol, 13: 65-71.

3. Beltrami AP, Urbanek K, Kajstura J, Yan SM, Finato N, Bussani R, Nadal-Ginard B, Silvestri F, Leri A, Beltrami CA, Anversa P (2001) Evidence that human cardiac myocytes divide after myocardial infarction. N Engl J Med, 344: 1750-1757.

4. Bronzini E, Novi AM (1959) Contributo anatomopatologico allo studio del cuore adiposo Studio su 100 casi. Arch Maragliano, 15: 1045-1070.

5. Hori $Y$, Funabashi N, Uehara M, Ueda M, Takaoka H, Nakamura K, Murayama T, Komuro (2010) Positive influence of aging on the occurrence of fat replacement in the right ventricular myocardium determined by multislice-CT in subjects with atherosclerosis. Int J Cardiol, 142: 152-158.

6. Imada M, Funabashi N, Asano M, Uehara M, Hori Y, Ueda M, Komuro I (2007) Epidemiology of fat replecement of the right ventricular myocardium determined by multislice computed tomography using a logistic regression model. Int J Cardiol, 119: 410-413.

7. Jacobi AH, Gohari A, Zalta B, Stein MW, Haramati LB (2007) Ventricular myocardial fat: CT findings and clinical correlates. J Thorac Imaging, 22: 130-135.
8. Kiès $P$, Bootsma $M$, Bax J, Schalij MJ, van der Wall EE (2006) Arrhythmogenic right ventricular dysplasia/ cardiomyopathy: screening, diagnosis, and treatment. Heart Rhythm, 3: 225-234.

9. Kim E, Choe YH, Han BK, Kim SM, Kim JS, Park SW, Sung J (2007) Right ventricular fat infiltration in asymptomatic subjects: observations from ECG-gated 16-slice multidetector CT. J Comput Assist Tomogr, 31:22-28.

10. Kimura F, Matsuo Y, Nakajima T, Nishikawa T, Kawamura S, Sannohe S, Hagiwara N, Sakai F (2010) Myocardial fat at cardiac imaging: how can we differentiate pathologic from physiologic fatty infiltration? Radiographics, 30: 1587-1602.

11. Kirsch J, Johansen CK, Araoz PA, Brady PA, Williamson EE, Glockner JF (2010) Prevalence of fat deposition within the right ventricular myocardium in asymptomatic young patients without ventricular arrhythmias. J Thorac Imaging, 25: 173-178.

12. Marcus FI, Fontaine GH, Guiraudon G, Frank R, Laurenceau JL, Malergue C, Grosgogeat $Y$ (1982) Right ventricular dysplasia: a report of 24 adult cases. Circulation, 65: 384-398.

13. McKenna WJ, Thiene G, Nava A, Fontaliran F, Blomstrom-Lundqvist C, Fontaine G, Camerini F (1994) Diagnosis of arrhythmogenic riht ventricular dysplasia/ cardiomyopathy. Task Force of the Working Group Myocardial and Pericardial Disease of the European Society of Cardiology and of the Scientific Council an Cardiomyopathies of the International Society and Federation of Cardiology. $\mathrm{Br}$ Heart J, 71: 215-218.

14. Raney AR, Saremi F, Kenchaiah S, Gurudevan SV, Narula J, Narula N, Channual S (2008) Multidetector computed tomography shows intramyocardial fatdeposition. J Cardiovasc Comput Tomogr, 2: 152-163.

15. Su L, Siegel JE, Fishbein MC (2004) Adipose tissue in myocardial infarction. Cardiovasc Pathol, 13: 98-102.

16. Uehara M, Takaoka H, Ozawa K, Kobayashi Y, Funabashi N (2013) Clinical significance of fat infiltration in the moderator band and right ventricular myocardium in multislice CT, and its association with abnormal conduction seen in electrocardiogram. Int J Cardiol, 168: 352-356.

17. Winer-Muram HT, Tann M, Aisen AM, Ford L, Jennings SG, Bretz R (2004) Computed tomography demonstration of lipomatous metaplsia of left ventricle following myocardial infarction. J Computed Assist Tomogr, 28: 455-458.

18. Zafar HM, Litt DA, Torigian DA (2007) CT imaging features and frequency of left ventricular myocardial fat in patients with CT findings of chronic left ventricular myocardial infarction. Clin Radiol, 63: 256-262. 